\title{
La campaña contra los sacerdotes pederastas (1880-1912): un ejemplo de «pánico moral» en la España de la Restauración*
}

\author{
Francisco Vázquez García ${ }^{1}$ \\ Universidad de Cádiz \\ francisco.vazquez@uca.es
}

RESUMEN: En este artículo se trata de analizar la campaña promovida por la prensa republicana anticlerical de la Restauración española contra los abusos cometidos por sacerdotes "pederastas». A partir de un conjunto aproximado de cuatrocientas noticias sobre el asunto, recogidas de la prensa anticlerical de la época (1880-1912), se ha constatado un total de 151 casos referidos a abusos pederastas perpetrados por el clero. La metodología utilizada se basa en la sociología norteamericana de los «pánicos morales». Después de introducir el problema, las fuentes y la cronología, se delimitan las fases que jalonan ese proceso de construcción del pánico moral acerca de los sacerdotes pederastas. Se pone de relieve el paralelismo existente entre la mencionada campaña periodística y la creciente ofensiva anticlerical entre 1898 y 1912. Por último la cruzada periodística contra los curas pederastas es analizada como un catalizador político de luchas que implicaban al mismo tiempo la dominación de género, de edad y de clase social.

\section{PALABRAS CLAVE: anticlericalismo; prensa; pánico moral; sacerdotes pederastas; Restauración.}

The anticlerical campaign against paedophile priests (1880-1912): an example of "moral panic" in Restoration Spain

* Este trabajo se ha llevado a cabo en el marco de una investigación colectiva sobre historia cultural de la sexualidad en España, dentro del grupo de investigación «El problema de la alteridad en el mundo actual» (Plan Andaluz de Investigación, Desarrollo e Innovación, Grupo HUM-536, Consejería de Conocimiento, Investigación y Universidad).

${ }^{1}$ ORCID iD: https://orcid.org/0000-0003-3950-4313. 
ABSTRACT: This article analyses the campaign promoted by the anticlerical republican press in Restoration Spain against the abuses committed by «paedophile» priests. Based on approximately 400 news items on the subject, taken from the anticlerical press of the time (1880-1912), a total of 151 cases related to pederasty abuses perpetrated by the clergy have been verified. The methodology used is based on the American sociology of «moral panics». After introducing the problem, the sources and chronology, the phases that mark the construction process of this moral panic regarding pederast priests are delineated. Attention is then drawn to the parallelism between the aforementioned journalistic campaign and the growing anticlerical offensive between 1898 and 1912. Finally, the journalistic crusade against paedophile priests is analysed as a political catalyst for struggles that also involve the domination of gender, age and social class.

KEY WORDS: anticlericalism; press; moral panic; paedophile priests; Restoration.

CÓMO CITAR ESTE ARTÍCULO/CITATION: Vázquez García, Francisco, «La campaña contra los sacerdotes pederastas (1880-1912): un ejemplo de "pánico moral" en la España de la Restauración», Hispania, 78/260 (Madrid, 2018): 759-786. https://doi.org/10.3989/hispania.2018.018.

\section{INTRODUCCIÓN. LOS CURAS PEDERASTAS Y LA EMERGENCIA DE UN «PÁ- NICO MORAL» EN LA RESTAURACIÓN}

Una larga herencia europea de anticlericalismo tradicional, de índole popular, también presente en España, muestra al sacerdote como un individuo especialmente lujurioso. El refranero, la tradición oral, las representaciones literarias, los procesos inquisitoriales por sodomía o solicitación, vehiculan este estereotipo que llega hasta nuestros días ${ }^{2}$. Junto a la barraganía y el concubinato, el adulterio o el sexo sacrílego con profesas, circula también la imagen de numerosos frailes que sodomizan a novicios ${ }^{3}$, de curas solicitantes que aprovechan la confesión para tener trato carnal con doncellas de tierna edad $^{4} \mathrm{o}$, en menor medida, con niños y adolescentes ${ }^{5}$. La construcción social del problema del cura pederasta en España, en el tránsito del siglo XIX al $\mathrm{XX}$, se nutre sin duda de esta tradición preexistente, pero supone un nuevo punto de partida. Lo que se pone en marcha desde la prensa anticlerical de la

2 CASTRO ALFIN, 1997: 73-82. PÉREZ LEDESMA, 2001: 234.

${ }^{3}$ CARRASCO, 1985: 139-142. BERCO, 2007: 111-112. RODRÍGUEZ, 2014: 146-166.

${ }^{4}$ DUFOUR, 1996: 121-123.

5 SARRIÓN MORA, 1994: 183-184. DUFOUR, 1996: 140-146. HALICZER, 1998: 188 y $234-235$. 
Restauración, es una campaña de alcance político, que puede ser analizada recurriendo a la sociología de los «pánicos morales» ${ }^{6}$.

Los escasos estudios de larga duración referidos a la historia del sexo con menores entre los siglos XIX y XX, particularmente en Francia y en Estados Unidos $^{7}$, señalan que la sensibilidad ante estas conductas ha seguido una pauta oscilante en los últimos 130 años, con fases de intensificación en las décadas de 1910, 1940 y desde 1980 hasta hoy, y ciclos de reflujo en las de 1920 y 1960. En los años de la «revolución sexual», durante la década de los 70, llegaron incluso a surgir en algunos países de occidente asociaciones en defensa de la pedofilia (la North American Man/ Boy Love Association o NAMBLA en Estados Unidos, el Front de Liberation des Pédohiles o FLIP y el Groupe de Recherche Pour une Enfance Différente o GRED en Francia), vinculadas al movimiento de gais y lesbianas ${ }^{8}$ y todavía a comienzos de los ochenta, el partido alemán de Los Verdes solicitaba en el Parlamento la reducción de las penas para las relaciones sexuales entre adultos y menores ${ }^{9}$.

Lo que, arrancando en la década de 1880 se designa, en periódicos como El Motín (fundado en 1881) o en Las Dominicales del Libre Pensamiento (fundado en 1883), con el término «pederastia», abarca conflictos que van más allá de lo que hoy designamos como «abusos sexuales a menores» ${ }^{10}$. El

${ }^{6}$ GOODE y BEN-YEHUDA, 2009.

7 El trabajo de AMBROISE-RENDU, 2014, centrado en Francia, abarca desde 1810 hasta la actualidad. El de DONOVAN, 1994, de carácter cuantitativo, abarca casi todo el siglo XIX. La cronología del estudio de JENKINS, 1998, focalizado en Estados Unidos, arranca en la década de 1890. Otro trabajo de JENKINS, 2001, se centra en la historia de los abusos pederásticos sacerdotales en Estados Unidos desde la década de 1980, pero incluye un capítulo sobre la previa tradición anticatólica en este país. Sobre Gran Bretaña no existe un trabajo equivalente, aunque hay dos excelentes monografías (BEHLMER, 1982. JACKSON, 2000) sobre el periodo victoriano, una más general, sobre el child abuse, incluyendo principalmente el maltrato y otra más específica, sobre el child sexual abuse. Sobre los abusos sexuales de menores en la Viena de Freud, WOLFF, 1988. Para España no existe ningún estudio general, pero pueden encontrarse análisis muy valiosos en el estudio de caso de WALKER, 2014, sobre la violación y asesinato del niño del Escorial en 1892.

8 JENKINS, 1998: 156-163. AMBROISE-RENDU, 2014, pos. 2963-3234.

9 SÁNCHEZ, 2013.

${ }^{10}$ En el Código de 1870, el artículo 453, referido a los delitos de violación y abusos deshonestos, establece en 12 años la edad del consentimiento, de modo que por debajo de esa edad, todo ayuntamiento carnal se considera violación. El artículo 454 considera también como «abuso deshonesto» todos los demás actos sexuales con personas «de uno u otro sexo», menores de 12 años. Ese era por ejemplo el caso de la sodomización de un niño o una niña. Por otro lado, el artículo 458, considera «estupro» toda relación sexual con una doncella mayor de 12 años y menor de 23 , si es perpetrada por «autoridad pública, sacerdote, criado, doméstico, tutor, maestro o encargado por cualquier título de la educación o guarda de la estuprada», o por cualquier persona, si media engaño. Finalmente, el artículo 459 establece el delito de «corrupción de menores» para el que «habitualmente o con abuso de autoridad, o confianza, pro- 
chantaje de un sacerdote por «golfos» veinteañeros, la violación de niñas, los tocamientos a un enfermo ingresado en el manicomio, los encuentros sexuales entre seminaristas o la flagelación «lúbrica» de un escolar, entraban dentro de la categoría en cuestión.

En un proceso de «pánico moral» se distinguen por una parte los «empresarios morales» que ponen en marcha las campañas definiendo el problema y por otra los grupos de presión que las respaldan; se localizan también los folk devils, es decir, los sujetos acusados y perseguidos por la acción colectiva y convertidos en chivos expiatorios ${ }^{11}$. Como se verá, el miedo a los desmanes protagonizados por curas pederastas surgió en la España de la Restauración a partir de la campaña promovida por ciertos círculos políticos y periodísticos. Ahora bien, esa campaña sólo cuajó dando lugar a un extendido pánico moral en el contexto de la crisis política y social del 98 y en relación con preocupaciones y conflictos de gran alcance, como los referidos a la «cuestión escolar» y a la protección de la infancia, dentro del antagonismo exacerbado entre clericalismo y anticlericalismo. Como han mostrado Julio de la Cueva y Feliciano Montero, clericalismo y anticlericalismo, a partir de la crisis del 98, se consolidan como movimientos «reactivo-defensivos» ${ }^{12}$, de modo que la denuncia en la prensa anticlerical de un ataque sexual perpetrado contra un menor por un sacerdote, desencadenaba una reacción contraria en los periódicos y en las iniciativas del activismo católico, que presentaban el caso como una calumnia, abriéndose de este modo un ciclo conflictivo más o menos prolongado. En ese escenario se articularon antagonismos que involucraban a la vez, en mutua interacción, a las identidades de clase, de género, de edad y de nacionalidad. Este trabajo se localiza por tanto en relación con dos de las tres vías interpretativas que se han diferenciado recientemente en el ámbito de los estudios históricos centrados en el anticlericalismo: el anticlericalismo como discurso de identidad y alteridad y el anticlericalismo como movimiento secularizador ${ }^{13}$. En conexión con lo primero, la historiografía del anticlericalismo (tanto española como internacional, pues el fenómeno debería ser considerado a escala comparativa trasnaciona ${ }^{14}$ ), cuando se ha ocupado tangencialmente

moviere o facilitare la prostitución o corrupción de menores de edad para satisfacer los deseos de otro» (Código penal reformado, 1870: 116-117).

${ }^{11}$ BECKER, 1985: 171-188. GOODE y BEN-YEHUDA, 2009: 109-128.

12 DE LA CUEVA y MONTERO, 2000: 59.

${ }^{13}$ DITTRICH, 2016: 133

${ }^{14} \mathrm{La}$ infancia, su protección y su socialización en clave de identidad nacional, desempeñó un papel importante a la hora de catalizar las luchas emprendidas desde finales del siglo XIX por los grupos anticlericales y anticatólicos en Europa y en Estados Unidos. España en esto, como en otras facetas de su anticlericalismo, no constituye una excepción (DITTRICH, 2016: 132). Sería no obstante interesante, aunque trasciende la perspectiva de este artículo, partir del estudio de algunos casos célebres de niños secuestrados o agredidos sexualmente 
de la mencionada campaña, lo ha hecho subsumiendo la construcción de las identidades de edad en el estudio sobre la construcción de las identidades nacionales y de género, de modo que la singularidad de la infancia y de los ataques sexuales perpetrados contra ella, quedaban en buena medida desdibujados. En relación con lo segundo, se trata de enmarcar las denuncias de la prensa dentro de las "guerras culturales» ${ }^{15}$ emprendidas por los grupos anticlericales para impulsar la secularización, disputando a sus rivales el control de la infancia y de su socialización, especialmente en los ámbitos de la escuela, la familia y las políticas protectoras de la niñez.

Para el análisis de la mencionada campaña partimos de un repertorio aproximado de 150 casos de abusos extraídos a partir de unas 400 piezas periodísticas de índole diversa (crónicas de casos, artículos de fondo, ilustraciones, ripios, canciones) situadas entre 1880 y 1912. Proceden principalmente de periódicos y semanarios anticlericales vinculados al republicanismo radical y a los círculos masónicos de librepensadores : El Motín, Las Dominicales del Libre Pensamiento y El País, editados en Madrid; El Diluvio, La Tomasa, Campana de Gràcia y La Publicidad, editados en Barcelona ${ }^{16}$.

por eclesiásticos — como el del niño judío Edgardo Mortara en Italia, el de Gaston Foveaux en Francia o el de Ernesto Jiménez en España - para trazar un perfil comparado de las reacciones anticlericales en distintos países. El caso Mortara ha sido estudiado con detalle (contrastando su recepción en Francia y Estados Unidos), resaltando la invasión clerical del espacio doméstico, por el historiador australiano Timothy VERHOEVEN, 2010: 57-73. Véase también KERTZER, 2017. Sobre Gaston Foveaux y la atribución de su violación y asesinato al hermano Flaminio, JANSOONE, 2001. SCHAEFFER, 2008: 87-92. AMBROISE-RENDU, 2009; 2014, pos. 1150-1214. Del caso de Ernesto Giménez, supuestamente violado en Barcelona por el escolapio Román Solé y Biel, nos ocupamos en un libro actualmente en preparación.

${ }^{15}$ Sobre el concepto de «guerra cultural» y su aplicación al conflicto entre clericales y anticlericales desde una perspectiva trasnacional, CLARK y KAYSER, 2003. También KAYSER, 2003. Dentro del volumen colectivo coordinado por estos historiadores, se incluye un capítulo sobre España, donde Julio De la Cueva utiliza el mencionado concepto en el contexto de un estudio de caso sobre la ciudad de Santander, DE LA CUEVA, 2003.

16 Para los casos que suscitaron mayor escándalo y atención, hemos consultado también la prensa independiente, de orientación liberal (periódicos como El Imparcial, Heraldo de Madrid, La Correspondencia de España, El Liberal), así como otros rotativos de orientación republicana de alcance nacional o local. En esos casos, y para contrastar los contenidos de los diarios del republicanismo radical, hemos recurrido a la prensa conservadora, ultracatólica y carlista (La Época, El Siglo Futuro, La Avalancha). Asimismo, para confrontar la presencia de estos casos en la prensa obrera, se han consultado periódicos de orientación socialista $(E l$ Socialista) y anarquista (La Revista Blanca). 


\section{LAS FASES DEL PROCESO. EL PARALELISMO ENTRE LA CAMPAÑA ANTIPEDE- RÁSTICA Y LA OFENSIVA ANTICLERICAL (1898-1912)}

En la primera etapa de la campaña, que llega aproximadamente hasta 1898, el fenómeno de los ataques pederásticos se presentaba como especialmente grave en Francia. Esto revela, como se ha dicho ${ }^{17}$, lo interconectadas que estaban entre sí en toda la Europa tardo decimonónica, las guerras culturales entre clericales y anticlericales. La prensa española aludía a la gallardía del gobierno y de los jueces de la Tercera República, decididos a detener y a dictar sentencia contra los sacerdotes responsables ${ }^{18}$. Se denunciaba al mismo tiempo la complicidad de la magistratura y de los gobernantes españoles con los «sátiros ensotanados», encubriendo unos acontecimientos cuya frecuencia debía ser mucho mayor de lo que salía a la luz. No obstante, en esa primera etapa se tendía a afirmar que los abusos pederásticos eran principalmente un «mal francés» ${ }^{19}$. Por eso se realizó una cobertura especial en casos como el de la colonia-hospicio de Citeaux, regentada por los Hermanos de San José, donde más de una docena de frailes fueron detenidos - con alguna fuga añadida-, en el verano de 1888 por abusar de un buen número de adolescentes internos ${ }^{20}$. Incluso los casos españoles más graves y más ampliamente glosados por la prensa, como el del profesor del seminario de Corbán (Cantabria $)^{21}$, en los primeros meses de 1888 , o el que implicó a Joseph Labré, di-

17 CLARK y KAISER, 2003: 4. Sobre la Tercera República francesa y su guerra cultural contra el clericalismo como modelo de los anticlericales de Bélgica y de la del Sur de Europa (España, Italia, Portugal), KAISER, 2003: 66 y 70.

18 «Los tribunales franceses condenaron a varios soldados de esta seráfica milicia por abusos deshonestos y corrupción de menores. ¡Solamente en una nación de impíos y ateos como Francia puede atreverse a tanto un tribunal! De fijo que en España hubieran ido las cosas de tan distinta suerte que probablemente los condenados habrían sido los muchachos del correccional por atreverse a calumniar a sus guardianes» (Las Dominicales del Libre Pensamiento, 4 mayo 1889).

19 «Aun cuando al establecer comparaciones se nos caiga la cara de vergüenza al ver cuán pocos de los nuestros están enchiquerados por esa causa, haciendo lo que hacen. ¡Porque cuidado si hacen, caballeros! Aunque en honor de la verdad, no tanto como en Francia, donde sólo en el año último hubo más de 240 profesores procesados por el delito de sodomía, dando la triste casualidad de que todos, lo que se dice todos, resultaron sacerdotes» («Manojo de Flores Místicas», El Motín, 4 noviembre 1886).

20 «Sodoma y Gomorra eclipsadas», El Motín, 19 julio 1888; «Los escándalos clericales en Francia», El Motín, 26 julio 1888; Las Dominicales del Libre Pensamiento, 29 julio 1888; Las Dominicales del Libre Pensamiento, 4 mayo 1889.

${ }^{21}$ «El seminario de Corbán y la pastoral del obispo», El Motín, 1 marzo 1888; «¡Chist!», El Motín, 8 marzo 1888; El Motín, 5 abril 1888; E. Ríofranco [R. Chíes]: «Corbán-Sodoma», Las Dominicales del Libre Pensamiento, 3 marzo 1888. 
rector del Colegio de los Hermanos de la Doctrina Cristiana en Madrid22, en la primavera de 1894, tuvieron como protagonistas a religiosos franceses.

¿Qué significado tiene esta referencia a la identidad nacional, en este caso francesa, dentro de la cruzada contra los abusos? La posición del país galo en la construcción de este pánico moral es ambigua y puede comprenderse vinculando la cuestión de la nacionalidad con la identidad de género, esto es, de la masculinidad, un asunto de creciente interés en la historiografía española sobre este periodo ${ }^{23}$. El Gobierno de la vecina república encarnaba, por una parte, el modelo al que aspiraban los círculos de librepensadores, los miembros de las logias masónicas y los integrantes de los cenáculos republicanos que promovían la campaña desde la prensa anticlerical, de ahí su «francofilia» ${ }^{24}$. Azote del poder despótico y reaccionario de la Iglesia Católica, bastión del laicismo y de la subordinación de la religión a los poderes públicos, Francia era también un ejemplo de nación «viril». Un Estado que contrastaba con la pusilanimidad, por no hablar de la connivencia, de la administración española con las autoridades eclesiásticas ${ }^{25}$.

Pero por otra parte Francia, y en especial su capital, se asociaban con los excesos del erotismo en sus formas más desenfrenadas y exóticas. La inversión sexual, el homosexualismo, se consideraban a menudo como males venidos de allende los Pirineos ${ }^{26}$, desviaciones que habrían contribuido a la despoblación del hexágono y al debilitamiento de su vigor, como la guerra franco-prusiana había puesto de manifiesto ${ }^{27}$. En esa misma estela se localiza, al menos en esta primera etapa de la campaña antipederástica, el miedo suscitado por la prensa anticlerical española ante la posible invasión del suelo español por crecientes oleadas de sacerdotes franceses con perversas inclinaciones, expulsados por las políticas religiosas del país vecino ${ }^{28}$. Estos sacerdotes emigrados, recibidos con los brazos abiertos por los gobiernos de la Restauración, se incorporaban principalmente al campo de la enseñanza.

22 «Más pequeñeces», El Motín, 13 mayo 1894. «iQue no es un cura, bah!», El Motín, 13 mayo 1894. «Los de la Fulla», El Diluvio, 14 mayo 1894. «¿Padres de familia o de los jesuitas?», El Diluvio, 16 mayo 1894. Las Dominicales del Libre Pensamiento, 25 mayo 1894.

23 ÁlVAREZ JUNCO, 1998. SALOMÓN CHÉLIZ, 2002. CHARNON-DEUTSCH, 2014-15. ARESTI, PETERS y BRÜHNE, 2016. MIGUÉLEZ-CARBALLEIRA, 2017. ZABALGOITIA HERRERA, 2017.

${ }^{24}$ SANABRIA, 2009: 125.

25 «Esa Francia, esa Francia... Por cometer estos atropellos con el pobrecito clero, se halla sin duda tan próspera y tan fuerte» («Respuesta», El Motín, 9 septiembre 1899). Sobre la imagen idealizada de Francia y de su política eclesiástica entre los anticlericales republicanos españoles, SALOMÓN CHÉLIZ, 2002: 492-493.

${ }^{26}$ VÁZQUEZ GARCÍA Y CLEMINSON, 2011: 40-41.

27 VÁZQUEZ GARCÍA Y CLEMINSON, 2011: 177.

${ }^{28}$ SUÁREZ CORTINA, 1998: 153. AUBERT, 2002: 223. ÁLVAREZ JUNCO, 2005: 341. SANABRIA, 2009: 86. 
Se ha dicho que desde el Concordato de 1851 y gracias a una generosa interpretación del mismo por los gabinetes conservadores, la Iglesia católica española habría conquistado el predominio de la educación secundaria, amenazando con extender su imperio sobre la enseñanza primaria ${ }^{29}$. Esta lectura es inexacta ${ }^{30}$. Las medidas antisecularizadoras en materia de instrucción pública adoptadas por el partido moderado de Bravo Murillo, fueron en parte revertidas durante el Bienio progresista posterior ${ }^{31}$. La Ley Moyano de 1857 establecía la preeminencia de los institutos provinciales públicos sobre los colegios privados. Los estudiantes de éstos debían abrir sus expedientes en los centros públicos y abonar allí la mitad de sus tasas, financiando así a los institutos $^{32}$. Fue paradójicamente la legislación educativa del Sexenio Revolucionario, la que, en nombre de la libertad de enseñanza, abrió la instrucción pública a las iniciativas de los sectores progresistas (como la Institución Libre de Enseñanza), pero también permitió a la Iglesia extender su presencia en este campo ${ }^{33}$. Los colegios privados de dirección eclesiástica sólo llegaron a ser predominantes entre 1894 y $1901^{34}$; a partir de entonces, las reformas introducidas por Romanones, que reforzaban el papel del Estado en la gestión de la enseñanza, revirtieron el proceso ${ }^{35}$.

Pues bien, los sacerdotes franceses, que desde 1880, con los primeros decretos anticlericales, habían comenzado a cruzar la frontera española ${ }^{36}$, se integraron pronto en esta red de colegios en expansión, incorporándose a los ya existentes o abriendo otros de nueva planta. El énfasis en la corrupción sexual de los menores por parte del clero galo era una advertencia a los padres de familia españoles y presentaba a los gobiernos clericales de la Restauración como promotores de una plaga de pederastia y «estetismo» que hacía peligrar la virilidad de la patria ${ }^{37}$.

${ }^{29}$ ARANDILLA NAVAJO, 1979: 189.

${ }^{30}$ Debo a la profesora María Cruz Romeo la sugerencia de leer la obra de SIRERA MIRALLES, 2011, que obliga a revisar la interpretación tradicional acerca de la expansión de la enseñanza privada desde 1851.

${ }^{31}$ SIRERA MIRALLES, 2011: 25-26.

32 SIRERA MIRALLES, 2011: 309.

33 SIRERA MIRALLES, 2011: 314-316.

${ }^{34}$ SIRERA MIRALLES, 2011.

35 SIRERA MIRALLES, 2011: 41-42.

36 DELAUNAY, 1981. MOLINA MARTÍNEZ, 1998: 299.

37 «Desde que se sabe que aquí campan por sus respetos todos los golfos con sotana y que no hay tribunal que se atreva a llevarlos a presidio, han tomado esto por una Jauja mística, donde los criminales colegiados ejercen de régulos y se imponen a grandes y pequeños. Ahora veremos si los diputados republicanos tienen coraje para protestar ante el país de la invasión frailuna que amenaza concluir con la poca vergüenza y los pocos recursos, y lo poco de hombres que todavía nos quedan» (El Motín, 18 mayo 1899). 
Ciertamente, el contexto de esta guerra cultural entre clericales y anticlericales por el control de la escuela («guerra escolar») ${ }^{38}$, no tenía el mismo sentido en Francia que en España. En el país vecino, los colegios de las congregaciones suponían un desafío porque ponían en riesgo la unidad nacional, al confrontar la juventud francesa educada en el integrismo católico, contrario a la Francia moderna y a sus instituciones, con la juventud formada en las escuelas laicas y en los valores republicanos. En España sin embargo, la presencia permanente de la religión en los centros públicos de enseñanza y la escasez de escuelas laicas privadas, no permitía la existencia de una rivalidad comparable a la que existía en Francia ${ }^{39}$. Más que la unidad, lo que se pretendía aquí era preservar la identidad nacional, amenazada por el afeminamiento colectivo que implicaba, tanto la formación de una juventud masculina con disposiciones principalmente religiosas (el mundo de la fe era considerado un mundo «mujeril») ${ }^{40}$, como los abusos sexuales que extendían en ella el vicio del «estetismo».

En cualquier caso, la prensa anticlerical de la época destaca tanto la frecuencia de los atentados pederásticos como su novedad. Se trataría de un fenómeno incentivado específicamente por el régimen de la Restauración, entregado a proteger los privilegios de la Iglesia y sus inclinaciones despóticas ${ }^{41}$. Ni siquiera en la época del Sexenio Revolucionario, sugieren los periodistas, pese al florecimiento conocido entonces por las gacetas anticlericales, se había dado una avalancha semejante de abusos en seminarios e internados ${ }^{42}$.

A partir de 1898, no obstante, la campaña para concienciar al público de la gravedad adquirida por el problema, alcanzó una nueva dimensión. El hecho debe emplazarse a escala europea y no simplemente española; la frecuencia

38 WITTE, 2003: 118-126 efectúa un detallado análisis de la «guerra escolar» impulsada en Bélgica en el primer quinquenio de la década de 1880. Sin embargo no menciona en ningún momento el argumento anticlerical que presenta al colegio católico como un «criadero de pederastas» debido a los abusos deshonestos cometidos por los sacerdotes: de hecho, en esa misma época la prensa española recogía algunos de esos casos de «ultrajes al pudor» cometidos por sacerdotes belgas.

${ }^{39}$ Esta comparación en SALOMÓN CHÉLIZ, 2002: 491. Sobre la literatura historiográfica acerca de de las «dos Francias», DITTRICH, 2016: 124.

40 SALOMÓN CHÉLIZ, 2002: 491; 2003: 44; 2005: 104-110. LOUZAO, 2008: 343.

41 «Está probado que cuanto más místico es un país y más abundan en él las órdenes religiosas, esos vicios van aumentando. En España desde la Restauración, ha tomado el mal proporciones aterradoras» («La escuela de Pamplona. Violación de niños. Escándalo monstruo», El País, 30 junio 1899).

42 «Este estado de cosas nadie negará que es privativo de la Restauración, porque tales casos eran rarísimos antes, prueba de ello el silencio de una prensa tan libre y tan anticlerical como la de la revolución, y que la de hoy, tan oprimida y rebajada, callando la mayor parte de las inmoralidades frailunas, sólo da cuenta de las más graves, cuyo número, en un año, excede al de toda la época de la revolución» («El crimen de un escolapio», El País, 11 junio 1902). 
con que la prensa recogía y comentaba casos de pederastia clerical acontecidos fuera de las fronteras españolas, indica que el fenómeno era un síntoma del recrudecimiento finisecular de la guerra cultural que enfrentaba entre sí a los sectores clericales y anticlericales de todo el continente. Aunque el número de casos recogidos por la prensa descendió respecto a la etapa anterior, pasando de 101 a 50, estos se concentraban ahora, principalmente, no en el país vecino, sino en el suelo patrio. Entre 1898 y 1912 hemos registrado en los diarios y semanarios anticlericales la presencia de 11 casos franceses por 31 españoles, más otros 8 acontecidos en terceros países. Algunos de estos casos lograron una repercusión hasta entonces desconocida, ocupándose de ellos no sólo los periódicos anticlericales, sino también la prensa de corte liberal e incluso los diarios obreros, vinculados al socialismo y al anarquismo ${ }^{43}$.

Así sucedió con el célebre episodio protagonizado en Lille (Francia) por el hermano Flaminio, acusado de violar y estrangular a un niño de doce años en el Colegio de los Hermanos de la Doctrina Cristiana a comienzos de 1899. Así ocurrió también en algunos sonados casos acontecidos en España. En primer lugar el suceso que tuvo como víctima al «cura Melías», apuñalado en Madrid en diciembre de 1898, probablemente extorsionado por un "golfo» con el que mantenía relaciones asiduas. El caso, cuya repercusión trascendió el ámbito de la prensa anticlerical ${ }^{44}$, fue comentado por plumas tan destacadas como Pío Baroja o Emilia Pardo Bazán ${ }^{45}$ y condujo a denunciar la frecuente presencia de sacerdotes en el submundo de la prostitución masculina y de los invertidos sexuales ${ }^{46}$. También hay que mencionar el caso del hermano Doro-

${ }^{43}$ El caso del hermano Flaminio, aparece comentado en El Socialista: «Este hecho, uno entre mil de la serie» (El Socialista, 17 febrero 1899), así como el del Padre Román, acaecido en Barcelona: «Cero y van. En Barcelona, un padre escolapio ha sido acusado de realizar actos repugnantes con los niños» (El Socialista, 18 julio 1902). El comentario de la publicación anarquista La Revista Blanca, en relación con este caso, es bastante más extenso: «Ni es el primero que ha cometido el pecado de sodomía (...) ni seguramente será el último» ( $L a$ Revista Blanca, 1 agosto 1902). En los medios anarquistas, los ataques contra el clero tenían mucho más predicamento que en los socialistas. Muchos libertarios leían con interés los artículos de Nakens en El Motín (SANABRIA, 2009: 116-117), y algunos, como Donato Luben, José María Blázquez y Máximo Maceiras, participaron en la campaña antipederástica con artículos específicos sobre el asunto.

${ }^{44}$ «El crimen de la calle de Trafalgar», El Liberal, 17 diciembre 1898. «Crimen misterioso. Un cura asesinado», El Heraldo de Madrid, 16 diciembre 1898. «El cura muerto», El Heraldo de Madrid, 16 diciembre 1898. «Sacerdote asesinado», La Izquierda Dinástica, 17 diciembre 1898. «Cura asesinado», El Heraldo de Madrid, 19 diciembre 1898.

45 P. Baroja: «Silvestre Paradox», El Globo, 21 enero 1901. E. Pardo Bazán: «La vida contemporánea», La Ilustración Artística, 23 enero 1899. E. Pardo Bazán: «La vida contemporánea. Como en las cavernas», La Ilustración Artística, 16 septiembre 1901.

46 «Se ha descubierto que el cura daba entrada en su casa a parte de esa escoria del Madrid corrompido y hambriento que lo mismo tima un reloj que se contrata para una empresa de 
teo, acaecido en Pamplona, un escolapio acusado de abusar de varios niños en la Escuela Pía de la capital navarra, en el verano de $1899^{47}$. O el escándalo suscitado a comienzos de 1900 en el seminario diocesano de Madrid, donde el homicidio de un profesor en manos de un novicio, dejó al descubierto toda una red de aprendizajes homoeróticos entre docentes y discentes ${ }^{48}$. $\mathrm{O}$ el caso del «cura de Carabanchel», acusado de violar salvajemente, en el verano de 1902, a una niña de 6 años cuando salía del colegio ${ }^{49}$. O especialmente, en fechas próximas al anterior, el caso del Padre Román, escolapio del colegio de la calle Ancha, detenido por violar a un niño de 7 años, un suceso que conmovió a la sociedad barcelonesa ${ }^{50}$. También fue en Barcelona donde se detuvo en otoño de 1901 al Padre Segismundo Prat, beneficiado de la Merced, por «abusos deshonestos homosexuales en menores de edad» ${ }^{51}$. La lista podría continuar con otro escolapio, esta vez del colegio de Valencia, el Padre Luis, acusado en noviembre de 1902 de golpear hasta la muerte y con «fruición genesíaca», al niño Luis Sáinz, de 7 años ${ }^{52}$. Esta intensidad en la calidad y cantidad de los sucesos, especialmente entre 1898 y 1902, pareció remitir parcialmente en los años siguientes. Pero sólo para reaparecer con fuerza a partir de 1908: un salesiano de Béjar (Salamanca) imputado en noviembre de

más importancia y que lo mismo se apresta a satisfacer apetitos brutales de hombres degenerados que comete un asesinato» (El Diluvio, 19 diciembre 1898).

47 «La escuela de Pamplona. Violación de niños. Escándalo monstruo», El País, 30 junio 1899. «Escándalo en Pamplona. Inmoralidades en la Escuela Pía», El País, 1 julio 1899. «Lo de Pamplona», El País, 4 julio 1899. «Cosas de ellos», El Motín, 6 julio 1899. «El escándalo de los Escolapios en Pamplona», Las Dominicales del Libre Pensamiento, 6 julio 1899. «Lo de Pamplona», El País, 12 julio 1899. «Pamplona religiosa. El obispo, los escolapios y la prensa», El País, 27 noviembre 1899.

48 «Podadera millonario», El País, 19 enero 1900. «El seminario de Madrid. Una sentina de fango», El País, 27 agosto 1901. «El seminario de Madrid. Estetismo», El País, 1 septiembre 1901.

49 «Atentado salvaje. Un cura preso», El Motín, 16 agosto 1902. «El crimen de un cura», El País, 15 agosto 1902; «Desde Carabanchel», El País, 17 agosto 1902. «Los neos y el cura de Carabanchel», El País, 18 agosto 1902. «El sátiro de Carabanchel», El País, 21 agosto 1902.

50 «Los crímenes del clericalismo. Un flaminio en acción», El Diluvio, 8 julio 1902. «Los crímenes del clericalismo. Un escolapio en la cárcel», El Diluvio, 9 julio 1902. «Los crímenes del clericalismo. Enseñanzas», El Diluvio, 10 julio 1902. «El crimen de un escolapio», El País, 11 julio 1902. «El escolapio sodomita», El País, 12 julio 1902. «Los crímenes del clericalismo», La Publicidad, 12 julio 1902. «La impunidad del clericalismo», La Publicidad, 12 julio 1902 (noche). «Crimen contra natura», Las Circunstancias. Diario republicano gubernamental, 13 julio 1902. «El escolapio sodomita», El País, 15 julio 1902. A. Marsillach y Costa, «Argucias periodísticas», El Diluvio, 16 julio 1902 (noche).

${ }^{51}$ S. Pey Ordeix: «Un cura en el banquillo», La Publicidad, 10 octubre 1901. «Frutos del árbol clerical», El Motín, 12 octubre 1901. «San Estetismo bendito», El País, 8 noviembre 1901.

52 «Brutalidad frailuna o la pedagogía sangrienta», El País, 21 noviembre 1902; «El crimen del escolapio», El País, 22 noviembre 1902. «Nuevo crimen clerical», Las Dominicales del Libre Pensamiento, 29 noviembre 1902. «La España africana», El Motín, 29 noviembre 1902. 
ese año por abusar de varios escolares ${ }^{53}$; un presbítero de Crevillente (Valencia), que atacó a tres niñas en la sacristía (febrero de 1909) ${ }^{54}$; un cura de Cádiz que practicaba el homosexualismo junto a las murallas de la ciudad (marzo de 1910)55; nada menos que el obispo de Beja (Portugal), acusado de múltiples desmanes sodomíticos con sujetos de uno y otro sexo (marzo de 1910) ${ }^{56}$; un sacerdote de Oviedo, espantado por el público cuando trataba de manosear a un joven limpiabotas, en la vía pública (septiembre de 1910) ${ }^{57}$. Cataluña fue escenario en 1910 de dos nuevos crímenes de esta índole; la violación de una niña de 6 años por el capellán del Convento de Santa Isabel, en Barcelona (octubre) ${ }^{58}$ y los abusos de cuatro niños perpetrados por el Padre Busquets, director del Colegio de San Pedro Apóstol, en Reus (Tarragona), dos meses después 59 . A estos hay que sumar nuevos casos acaecidos entre 1910 y 1912 en Valencia, Ciempozuelos (Madrid) ${ }^{60}$, Toledo ${ }^{61}$, Manzanares (Ciudad Real) ${ }^{62}$, Achuri (Bilbao) ${ }^{63}$ y La Coruña ${ }^{64}$.

En esta nueva etapa, la cruzada periodística no se quedaba sólo en la mera acumulación de noticias acusatorias. La indignación popular contra estos abusos, que hasta 1898 sólo había asomado ocasionalmente en la forma de protestas vecinales más o menos espontáneas ${ }^{65}$, se convirtió en un clamor cotidiano, que la propia prensa se ocupó de promover y canalizar. El caso Román, por ejemplo, dio lugar en Barcelona a la puesta en marcha (animada por El Dilu-

53 «Frutos de la enseñanza religiosa. Otro Flaminio», El Pueblo, 8 julio 1908; «Salesiano fresco», El Motín, 19 noviembre 1908.

54 «Manojo de Flores Místicas», El Motín, 4 febrero 1909.

55 «En broma y en serio», El Demócrata (Cádiz), 9 marzo 1910.

56 «Para el mitin clerical», La Voz de Menorca, 18 marzo 1910. «Un obispo acusado de sodomita», El Pueblo. Órgano del Partido Republicano de Tortosa, 19 marzo 1910.

57 «Cura sodomita», El Motín, 1 septiembre 1910.

58 «Crimen abominable», El Motín, 20 octubre 1910.

59 «Otro caso», El Motín, 15 diciembre 1910. Fray Gerundio [Albinio Juste]: «¿Venganza o moralidad?», El Motín, 13 abril 1911.

${ }^{60}$ «Ciempozuelos. El convento del crimen», El Motín, 10 noviembre 1910. «Los horrores de Ciempozuelos», El País, 5 mayo 1912.

${ }^{61}$ Fray Gerundio [Albinio Juste]: «¿Venganza o moralidad?», El Motín, 13 abril 1911.

62 «Los Maristas», El Motín, 2 noviembre 1911.

63 «Buena pullita», El Motín, 4 abril 1912.

64 «Quien ama el peligro», El Motín, 13 junio 1912. «Lo del Colegio Católico», El Motín, 4 julio 1912.

${ }^{65}$ Por ejemplo, a raíz del caso del Padre Luciano Sánchez, capellán de un convento de monjas en Salamanca, que en octubre de 1890 persiguió y asaltó sexualmente en descampado a un criado de 17 años. Detenido por un sereno y un guardia municipal, el sacerdote fue «conducido a la prevención del ayuntamiento, se amontonó el pueblo y hubo una silba fenomenal con ‘¡mueras!' (...) y la silba y la protesta contra el cura tomaba proporciones tan peligrosísimas para la integridad de su persona, que acudió el gobernador e hizo disolver los grupos» («El clérigo sodomita de Salamanca», Las Dominicales del Libre Pensamiento, 4 octubre 1890). 
vio, periódico de inspiración anticlerical), de acciones judiciales de acusación popular ${ }^{66}$. Se programaban manifestaciones y mítines anticlericales dirigidos específicamente contra esta «epidemia» ${ }^{67}$. Las logias y los círculos de librepensadores, las agrupaciones republicanas, los sindicatos de maestros ${ }^{68}$ y las ligas anticlericales, que proliferaron a partir de $1900^{69}$, intervenían activamente en estas iniciativas, denunciando las fechorías cometidas en los seminarios y las escuelas confesionales, protestando contra la complicidad y el encubrimiento promovidos por la magistratura, la prensa del establishment, el gobierno y las autoridades eclesiásticas. Pero sobre todo advertían a las familias acerca del peligro que arrostraban cuando matriculaban a sus hijos en estos «antros» $\rangle^{70}$. La campaña llegó incluso a proyectarse en iniciativas parlamentarias, imitando lo realizado por los diputados socialistas franceses a raíz del caso Flaminio ${ }^{71}$. Se pretendía que los representantes republicanos - Blasco Ibáñez, Lerroux, Rodrigo Soriano, entre otros-, presentasen propuestas vetando a las órdenes religiosas el ejercicio de la enseñanza ${ }^{72}$.

66 «Los crímenes del clericalismo. La opinión pública. La acción popular», El Diluvio, 12 julio 1902.

${ }^{67}$ «Se nos ha convocado a que convocáramos a una reunión magna a todas las sociedades y entidades progresivas, democráticas y liberales de esta» («Los crímenes del clericalismo. La opinión pública. La acción popular», El Diluvio, 12 julio 1902).

${ }^{68}$ Véase la propuesta para que la Unión de Profesores Particulares de Barcelona entable acción popular «en el proceso del escolapio P. Román Solé» («Crimen contra natura», Las Circunstancias. Diario republicano gubernamental, 13 julio 1902).

${ }^{69}$ SUÁREZ CORTINA, 1998: 164-169.

70 «El castigo que merecen esos clericales debe ser severo y ejemplar, y a los verdaderos padres que mandan a sus hijos a esos antros de perversión humana se les debería dar una corrección. Así escarmentarían» («Nuevo sátiro ensotanado», Las Dominicales del Libre Pensamiento, 18 julio 1902).

${ }^{71}$ E. Blasco: «El crimen de Lille», El Motín, 16 febrero 1899.

72 Alejandro Lerroux, reclamando medidas para cerrar los colegios religiosos que enseñen doctrinas contrarias a la Patria, aludió al caso Flaminio en una sesión de Las Cortes, celebrada en 1906 (Diario de las Sesiones de Cortes, sesión del sábado, 15 diciembre de 1906: 4612). El propio Lerroux ya había intervenido en el Congreso en noviembre de 1902, respondiendo al diputado conservador Peris Mencheta. Este consideraba una infamia acusar al escolapio valenciano P. Luis, de haber asesinado al niño Sáinz de una brutal paliza (comparaba la infamia con la vertida contra el Padre Román, el escolapio de Barcelona). Lerroux, apoyando la posición de Rodrigo Soriano, le preguntó a Peris si estaba al tanto del secreto del sumario Diario de las Sesiones de Cortes, sesión del sábado, 25 noviembre 1902: 1448. Anteriormente, en junio de 1899, Blasco Ibáñez había intervenido en el Congreso solicitando que se castigaran los delitos cometidos en Pamplona por el Hermano Doroteo: «porque hoy que se habla tanto de regeneración, si a la juventud que salga de estas escuelas religiosas, al mismo tiempo que se le enseña los principios de la ciencia, se descorre ante sus ojos el velo de placeres asiáticos, en vez de crear una generación de hombres, una generación de Cides, sólo se creará un pueblo de Sporos y Corydones» (Diario de las Sesiones de Cortes, sesión del viernes, 30 junio 1899: 565). 
Algo que llama la atención en esta secuela de casos que arranca en 1898 es que el ciclo de la campaña antipederástica parece coincidir en su intensidad y en sus fluctuaciones, con el ciclo de la reacción anticlerical en general. Los historiadores están de acuerdo a la hora de localizar en la crisis de 1898, el despegue de una gran ofensiva anticlerical que tendría sus hitos principales a comienzos de siglo: la oposición al Real Decreto del Ministro Pidal y Mon (30 mayo 1900), ampliando el latín y la religión en la programación escolar; la publicación de un artículo del confesor del rey condenando el liberalismo (1900); el anuncio de la boda de la Princesa de Asturias con el carlista Conde de Caserta (1900); el ruidoso estreno de la Electra de Galdós (1900); o el escándalo suscitado por el caso de la señorita Ubao $(1901)^{73}$. La ofensiva anticlerical, que desembocó en las manifestaciones masivas de 1901, fue alentada por la presencia de un catolicismo cada vez más activo, mejor organizado y expansivo, extendiéndose en los ámbitos de la enseñanza y la beneficencia y penetrando en el mundo sindical, incentivado en su militancia bajo el pontificado de León XIII ${ }^{74}$. La oleada anticlerical creyó encontrar la oportunidad de frenar este avance durante los gobiernos liberales de la primera década del siglo, cuyas reformas apuntaban a potenciar la escuela pública y a separar la Iglesia del Estado: política educativa de Romanones en 1902 y tentativas de Canalejas, en 1901, 1906 y 1910 (Ley del Candado), para someter las órdenes religiosas a la Ley de Asociaciones, limitando su crecimiento ${ }^{75}$. Estos tímidos intentos del Estado para rebajar las prerrogativas eclesiásticas eran respaldados y superados desde las propuestas parlamentarias y sobre todo desde la calle, por una movilización anticlerical revitalizada, que acabó penetrando con fuerza en la agenda de los partidos obreros ${ }^{76}$. Tras el asesinato de Canalejas en 1912, coincidiendo con un reflujo del republicanismo, este impulso se desinflón ${ }^{77}$, y así sucedió también con la campaña dirigida contra los abusos pederásticos del clero.

\section{GÉNERO, EDAd Y CLASE. LA CAMPAÑA ANTIPEDERÁSTICA Y LA FABRICA- CIÓN DE ESPAÑOLES}

A partir de 1898, el problema de la invasión peninsular de los curas franceses expulsados por la Tercera República, se agravó con el retorno de los

73 DE LA CUEVA MERINO, 1997. SUÁREZ CORTINA, 1998: 129 y 159. DE LA CUEVA MERINO y MONTERO GARCÍA, 2000. PÉREZ LEDESMA, 2001: 246. AUBERT, 2002: 223 y 241. ÁLVAREZ JUNCO, 2005: 338-339. SANABRIA, 2009: 14.

${ }^{74}$ SUÁREZ CORTINA, 2014: 155-160.

75 SUÁREZ CORTINA, 2014: 167-171.

${ }^{76}$ SUÁREZ CORTINA, 2014: 172-177.

${ }^{77}$ SUÁREZ CORTINA, 2014: 184. 
frailes y sacerdotes repatriados tras la pérdida de las últimas colonias ${ }^{78}$. La prensa anticlerical apuntó sobre todo contra los frailes españoles procedentes de Filipinas ${ }^{79}$. Corría el rumor de que la animadversión contra los colonizadores se había propagado en el archipiélago a raíz, entre otros, de los desmanes pederásticos perpetrados por el clero español con jóvenes filipinos ${ }^{80}$. Los curas que regresaban, por tanto, además de haber contribuido a la pérdida del Imperio, amenazaban ahora con extender la plaga del «estetismo» y la sodomía sobre el solar nacional.

El clero, encarnación de un pasado reaccionario, cuyo poder contribuía a hacer de España un país decadente y de segunda fila, al margen de las naciones modernas, controlaba, gracias a su presencia en el sistema escolar, la producción del futuro, esto es, de la infancia. La campaña contra los curas pederastas tenía por ello su eje principal en la niñez; la pugna por el control de la escuela y la pugna por la protección de la infancia. Por una parte, a comienzos del siglo XX, alcanzó su momento culminante la lucha entre clericales y anticlericales a propósito de la "cuestión escolar» ${ }^{81}$. La denuncia de atentados al pudor cometidos en los colegios religiosos tenía su contrapartida en la crítica clerical de las escuelas no confesionales, donde la religión cristiana desaparecía de los contenidos curriculares («escuela laica») o se situaba en el mismo nivel que los restantes credos («escuela neutra»). Desde las filas del clericalismo, la educación no confesional sólo conducía a facturar hombres $\sin$ Dios, futuros anarquistas y asesinos a sueldo ${ }^{82}$.

Por otro lado, como viene mostrando desde la década de 1990 una boyante historiografía, entre finales del siglo XIX y las primeras décadas del XX, se desarrolló en España el problema de la protección de la infancia ${ }^{83}$. Se trataba a la vez de la niñez «en peligro» (explotación laboral, desnutrición, maltrato físico, corrupción moral, mortalidad elevadísima) y de la niñez «peligrosa» (el problema del «golfo», la mendicidad y la vagancia, los «niños anormales» y «degenerados»). Entre 1900 y 1904 —en este año se publica la Ley de Pro-

78 SUÁREZ CORTINA, 1998: 154-155.

79 ÁLVAREZ JUNCO, 2005: 195.

80 «El obispo de Pamplona ha lanzado un decreto prohibiendo (...) la lectura y retención del semanario El Porvenir Navarro (...) por haber levantado el velo que cubre ciertos actos flaminios que se cometen en algunos asilos. Y por haber demostrado que los únicos causantes de la pérdida del archipiélago filipino, fueron los frailes» (El País, 27 noviembre 1899). «Que si hay un jesuita muy amable con los jóvenes varones» (NAKENS, 1915: 140).

${ }^{81}$ SUÁREZ CORTINA, 1998: 188-203.

82 Por ejemplo: «Consecuencias de la educación laica», La Avalancha, 23 diciembre 1911.

${ }^{83}$ FERNÁNDEZ SORIA y MAYORDOMO PÉREZ, 1984. ÁLVAREZ URÍA y VARELA, 1991. BALLESTER y BALAGUER, 1995. BORRÁS LLOP, 1996. PERDIGUERO GIL, 2004. BARONA, 2007. LOREDO NARCIANDO y JIMÉNEZ ALONSO, 2014. LOREDO NARCIANDI, 2016. DEL CURA GONZÁLEZ, 2011. 
tección de la Infancia-, se aprueba un amplio conjunto legislativo que apuntaba a afrontar este problema ${ }^{84}$. Se pretendía sacar a los niños de la calle y de los talleres para encuadrarlos en el sistema escolar. Este será asimismo otro de los frentes de contienda entre clericalismo y anticlericalismo. Y en este espacio, la corrupción moral y sexual, ocupaba un lugar central. Si las ligas católicas apuntaban a llevar la iniciativa en la lucha antipornográfica (fundación en 1911 de la Liga Contra la Pornografía ${ }^{85}$ y contra la «trata de blancas» (fundación en 1902 del Real Patronato contra la trata de blancas) ${ }^{86}$, las ligas anticlericales y la prensa librepensadora recrudecían la campaña contra los abusos pederásticos del clero.

El asunto de la escuela y del combate por la colonización de la infancia es inseparable de la cuestión del género. La reciente historiografía del anticlericalismo, cuestionando algunas explicaciones en clave atemporal, procedentes de la antropología ${ }^{87}$ y el psicoanálisis ${ }^{88}$, ha convertido al género y a la sexualidad en un elemento central de su agenda investigadora, pero en general, no ha explorado la particularidad que representa la variable de la edad, subsumiendo el tema de los abusos sexuales de la infancia en el motivo de la misoginia y de la lucha entre curas y cabezas de familia anticlericales por el control de las mujeres ${ }^{89}$. Hay que indagar no obstante las singulares relaciones que guardan entre sí la dominación de género y la dominación por la edad, entre sexismo y adultocentrismo, sin subsumir un problema en el otro. Se creía que los ataques de los curas pederastas en seminarios y centros escolares contagiaban el homosexualismo a los niños y deshonraban a las niñas, propa-

${ }^{84}$ FERNÁNDEZ SORIA y MAYORDOMO PÉREZ, 1984: 200-205. DEL CURA GONZÁLEZ, 2011: 47-50.

85 GUEREÑA, 2006; 2013: 348-351.

86 GUEREÑA, 2003: 375-383.

87 DELGADO, 1993; 2012.

88 CONARD, 1971. MITCHELL, 1998.

89 ÁLVAREZ JUNCO, 1990: 402; 2005: 343. SANFELIU, 2009. SANABRIA, 2009: 136. Para el periodo de la Guerra Civil, VINCENT, 2014 y THOMAS, 2014: 131-156, aunque ninguno de estos dos estudios alude a la pederastia clerical. Una de las historiadoras españolas del anticlericalismo que más detenidamente ha explorado la cuestión del género, sólo menciona las críticas anticlericales de la lujuria sacerdotal en relación con las mujeres (SALOMÓN CHÉLIZ, 2003: 45-52; 2005: 106; 2011). Cuando alude al discurso anticlerical sobre el «afeminamiento» de los jóvenes, lo hace en el contexto de la crítica al predominio de la enseñanza religiosa en las escuelas de las congregaciones, no en relación con el motivo de los «abusos pederásticos» (SALOMÓN CHÉLIZ, 2002: 491). A escala internacional, el texto que más se aproxima a nuestro enfoque, vinculando la construcción anticlerical de las identidades de género y nación (en Francia y en Estados Unidos) con la implantación de una sexualidad reproductiva contraria al celibato y a las perversiones eclesiásticas, es el de VERHOEVEN, 2010: 75-101 (sobre la controversia médica en torno al celibato eclesiástico) y 103-127 (sobre la representación de la masculinidad híbrida del jesuita). No obstante este autor no trata el tema de los ataques sexuales a menores. 
gando la afeminación por todo el organismo nacional. El equivalente de la pederastia en el ámbito doméstico lo constituía el adulterio clerical y la seducción sacerdotal de las hijas de familia. Este tema, muy difundido por la literatura (naturalismo radical, realismo) y el ensayo de la Restauración, presentaba a las mujeres como el instrumento que le permitía a la Iglesia Católica controlar los procesos de reproducción doméstica, mermando la masculinidad de los cabezas de familia ${ }^{90}$. El marido aparecía ninguneado, convertido en una marioneta a merced de la pareja formada por la esposa y el director espiritual. Si la escuela religiosa, a través de los abusos pederásticos, conducía a la desmasculinización de los hijos, la familia sometida al cura indicaba la desvirilización de los maridos.

Este nexo entre la pérdida de masculinidad y la pederastia en los colegios revela el papel central desempeñado por la escuela en los proyectos nacionalizadores, en los procesos de fabricación de españoles. La prensa anticlerical entendía que las escuelas católicas, donde se propagaba el contagio pederástico, producían una «anti-España» degenerada y afeminada. Esos centros promovían el «estetismo» y la subordinación de España a la alianza del sacerdote con las mujeres. La escuela laica o la escuela pública no confesional, sin embargo, constituían un antídoto contra este declive de la virilidad, un instrumento que rompía la coalición funesta entre el sacerdote y la esposa. Este asunto aparece formulado a menudo bajo la forma de una antítesis de identidades. El cura célibe, ajeno a los valores domésticos, de masculinidad viscosa y con propensión a la corrupción de menores, aparece como la antítesis del maestro.

En efecto, se pone en contraste la protección que el régimen de la Restauración ofrece a los sacerdotes, con su desinterés por la enseñanza en las escuelas públicas. Se acoge y sufraga generosamente a los frailes venidos de Francia o repatriados de Cuba y Filipinas, «desatendiendo al maestro de escuela y olvidando otros deberes $\gg{ }^{91}$. Se critica a las autoridades gubernamentales, convertidas en «maniquíes del elemento clerical» ${ }^{92}$, que abandonan a suerte a los maestros, dejándolos «sin un pedazo de pan que llevarse a la boca» ${ }^{93}$. Este descuido contrastaba con el ejemplo que, una vez más, representaba el Estado francés, con escuelas públicas, laicas y bien dotadas, y con un cuerpo de maestros destacado por su probidad ${ }^{94}$.

${ }^{90}$ FERNÁNDEZ, 1995: 178-188. LABANYI, 2000: 91-262. ÁLVAREZ JUNCO, 2005: 343-347. SANABRIA, 2009: 123-149. TSUCHIYA, 2011: 112-135.

${ }^{91}$ «El que tenga ojos para ver», El Motín, 1 octubre 1890.

92 S. Ardales: «Carta abierta al Sr. D. Ramón Hernández», Las Dominicales del Libre Pensamiento, 25 octubre 1901.

93 «Luz y sombra», Las Dominicales del Libre Pensamiento, 17 octubre 1902.

94 «Y en casa de los institutores franceses habitan el bienestar y la dignidad», «Luz y sombra», Las Dominicales del Libre Pensamiento, 17 octubre 1902. En La Publicidad, 10 octubre 1902, se publica el relato de Zola titulado Verdad. En él se narra el caso de violación y estrangu- 
Pero sobre todo, la prensa anticlerical contraponía la masculinidad célibe y por tanto enfermiza del sacerdote, que lo arrastraba hacia la sodomía, a la masculinidad saludable de los maestros. Ya Lerroux, en el curso de una sesión parlamentaria, había considerado improbable que los maestros fueran procesados por delitos «flaminios». Suelen ser «casados, honrados padres de familia» ${ }^{95}$, y cuando se da el caso de que el profesor es soltero, «fuera de las horas de clase hace la vida corriente, la que hacemos todos» ${ }^{96}$. Es decir, los sacerdotes que educan a los niños viven una existencia desnaturalizada, alejada de las mujeres y del calor doméstico, atada por un voto de castidad que les conduce, por la «ley natural de esta brutal naturaleza humana» ${ }^{97}$, a abusar de los que tienen más cerca. Y esa carencia de «amor familiar», que es la base del «amor patrio», los convierte en potenciales enemigos de la nación ${ }^{98}$.

Los textos periodísticos dejan así entrever lo que Connell y Messerschmidt han designado como «jerarquía de masculinidades» ${ }^{99}$. En la cúspide, en el emplazamiento de la masculinidad hegemónica, se halla el sujeto hetero y sexualmente activo, de condición seglar. La figura del maestro y padre de familia prolífica ocuparía ese lugar. En una segunda escala se encuentra la masculinidad heterosexual y eróticamente activa del sacerdote cohabitando con una «ama» que hace las veces de esposa ${ }^{100}$. No hay que olvidar que entre los colaboradores de la prensa anticlerical más militante contra la pederastia de los curas, se encuentran muchos sacerdotes de esta índole. Son los «curas renegados» ${ }^{101}$, como los denominaban sus detractores, en su mayoría amancebados con mujeres, sancionados por las autoridades eclesiásticas y convertidos en articulistas de El Motín, El País o Las Dominicales del Libre Pensa-

lamiento de un escolar a manos de un fraile en una escuela de religiosos. Estos maniobraron junto a la autoridad para inculpar a un tío del niño, que era judío y maestro de escuela.

95 «Lenguaje valiente», El Motín, 27 octubre 1900.

96 «El crimen de Lille», El Motín, 16 febrero 1899.

97 «El crimen de Lille», El Motín, 16 febrero 1899.

98 «Hoy el celibato sólo conduce a producir hombres extraños al medio en que viven, deformados psíquicamente, amputados de los afectos más tiernos de que es capaz el alma humana, desligados de los vínculos más fuertes e íntimos que nos unen a la sociedad. El que es buen padre es buen patriota. El amor a la patria tiene su raíz en el amor de la familia. ¿No habrá sido el secreto propósito de los Pontífices el romper así todo lazo del clero con la sociedad y con la patria para convertirle en instrumento ciego y pasivo de las voluntades de Roma?» (A. Calderón Arana: «Que se casen», El Motín, 29 abril 1905).

${ }^{99}$ CONNELL y MESSERSCHMIDT, 2005: 842.

100 «Gracias a que cada cura está provisto de su correspondiente ama; de lo contrario, ni las abominaciones de Sodoma tendrían punto de comparación con las de cualquier ciudad católica. Me arrepiento en este instante de haber puesto en ridículo a las amas de los curas, sin tener en cuenta que son importantísimo factor de moralidad pública y escudo y salvaguardia de jóvenes honrados», «Señor obispo de Lérida», El Motín, 4 noviembre 1886.

${ }^{101}$ MOLINA MARTÍNEZ, 1998: 313. 
miento. José Ferrándiz, Albinio Juste, Miguel Mir, Pey Ordeix, Ramón Sarmiento y Pérez Martinón, son algunos de los nombres más conocidos.

Por debajo del sacerdote secular con ama se localizan en esta gradación de masculinidades, los clérigos, también seculares, capaces de cumplir con el voto de castidad. Son pues heterosexuales pero eróticamente inactivos. Se trata de casos excepcionales, generalmente sujetos de cierta edad y formación, con una rica vida intelectual que les permite espiritualizar el instinto ${ }^{102}$. En el último escalón de la jerarquía se encontraba la masculinidad homosexual del fraile. El clero regular aparece así caracterizado por una lujuria desenfrenada, en contraste con el clero secular, que se consideraba más morigerado, más proyectado en el mundo y por tanto menos pervertido ${ }^{103}$. Este temperamento sanguíneo y caliente, propio de hombres rudos, de origen campesino, era violentado por la castidad obligatoria ${ }^{104}$. El resultado del celibato, en estos casos, resultaba fatal, pues llevaba a dirigir el instinto hacia los más próximos. Si el fraile ejercía como docente, las víctimas de sus impulsos serían los niños destinados a su cuidado.

Como sugiere esta última referencia al origen campesino de los frailes, las intersecciones entre género y edad involucraban también a las identidades de clase $^{105}$. Los políticos y periodistas que pusieron en marcha la cruzada contra la pederastia clerical y que aparecen como autores de los artículos, eran de procedencia muy dispar: profesores próximos a la Institución Libre de Enseñanza, maestros de escuelas laicas, masones y librepensadores, republicanos anticatalanistas, federales, radicales, independientes, socialistas católicos, sacerdotes «renegados» y escritores próximos al movimiento libertario. La sociología de los «pánicos morales» suele abordar estos procesos viéndolos como el resultado de grupos de presión que, guiados por «intereses objeti-

102 «Los hombres estudiosos e ilustrados, de alma un tanto grande y nobles sentimientos, pueden ser castos, porque viven entretenidos en el estudio y tienen recursos contra sus pasiones, ¿pero esos pezuños groseros recién arrancados del campo y de pronto vestidos con hábitos? Imposible esperar de ellos más que atrocidades» («Otro Flaminio», El País, 26 octubre 1899).

103 Aludiendo al caso de Manuel Sacristán Velasco, párroco ecónomo de Humanes (Madrid), condenado en 1885 a más de diez años de prisión por abusar de varios niños, El País contrasta la situación de los sacerdotes seglares, menos protegidos por la autoridad y por eso más proclives a ser condenados, con la de los miembros de órdenes religiosas, cuyos crímenes, siendo más graves y numerosos, tienden en cambio a quedar impunes (El País, 4 julio 1899).

104 «QQué ha de suceder entregando la niñez a esa gente brutal? Campesinotes robustos que dejan la azada y el pico para convertirse en maestros, pero maestros obligados a la castidad absoluta, comiendo bien y fuerte, bebiendo mejor, trabajando poco y en una vida la más a propósito para echar leña al fuego que ya por sí sola enciende la Naturaleza» («Violación de niños. Escándalo monstruo», El País, 30 junio 1899).

${ }^{105}$ La dimensión de clase involucrada en las guerras culturales entre clericales y anticlericales, se ha resaltado especialmente en los estudios acerca de los casos alemán y español y mucho menos en Francia (DITTRICH, 2016: 125-126). Véanse al respecto los trabajos de BORUTTA, 2010. DITTRICH, 2014. GROSS, 2004. 
vos», ponen en marcha campañas destinadas a perseguir un mal social que consideran en expansión ${ }^{106}$. Pero la idea de que existen «intereses objetivos» dados en la experiencia vivida, de modo que el discurso se limitaría a expresarlos, ya no es de recibo en la historia social ${ }^{107}$.

La propaganda contra la corrupción clerical de menores, una pieza en la vasta industria cultural del anticlericalismo de la Restauración, debe ser entendida más bien como una tecnología discursiva y visual que apuntaba a crear una «comunidad emocional» ${ }^{108}$ unida por el rechazo a la Iglesia y a su control sobre los procesos de reproducción social, de fabricación de españoles. Los actores de la campaña no conformaban un grupo con un rostro preestablecido y reconocible; más bien su identidad como tal se fue construyendo en el curso de la propia empresa propagandística. Y se trataba de una identidad de vocación expansiva; gracias al fuerte impacto emocional del asunto de los abusos pederásticos sacerdotales sobre la imaginación de las clases populares, la campaña facilitaba la proyección del discurso republicano pequeñoburgués en el universo de los partidos obreros ${ }^{109}$.

Aquí se inserta la retórica de clase que acompaña a los artículos e imágenes de la prensa anticlerical. El recurso al melodrama folletinesco permitía enfatizar la desproporción existente entre el sacerdote degenerado, miembro de órdenes opulentas, protegidas por el Estado, y el retoño de familia humilde pero respetable, situada en los límites de la indigencia. Por esta razón se resaltaban los actos cometidos contra niños y adolescentes de clase trabajadora o de clase media venida a menos. Los artículos no olvidaban por ejemplo, evocar las tentativas realizadas por las congregaciones y sus poderosos protectores, asociaciones y particulares vinculados a la nobleza y a la alta burguesía, para tapar los escándalos compensando económicamente a las familias, sobornando a terceros o recurriendo a prestigiosos abogados. Los periodistas aparecen entrando en los modestos hogares de las víctimas, donde retratan el cuadro desolador producido por el ultraje ${ }^{110}$. En ese escenario se localiza también la frecuente presencia de pederastas escolapios y de otras órdenes proyectadas en el cuidado y salvación de las clases menesterosas.

106 GOODE y BEN-YEHUDA, 2009: 143-144.

107 JONES, 1989: 20-21. ÁLVAREZ JUNCO, 1990: 386-387. CABRERA, 2001: 101-142.

108 FERNÁNDEZ, 2016.

109 Sobre el anticlericalismo como instrumento del radicalismo de Lerroux para atraer a la clase obrera al terreno republicano, construyendo un partido de masas, ÁLVAREZ JUNCO, 2005: 114. Sobre la estrategia similar de Nakens, SANABRIA, 2009: 62.

110 «Es una vivienda mísera. Todos los corazones caritativos deben acudir a ella para convencerse de la infamia. Francisca Fernández es viuda del inspector de policía Miguel Íñiguez, fallecido recientemente. Quedó abandonada a sus propias fuerzas, con cuatro niñas, dos algo mayores que trabajan en la fábrica de Rocamora contribuyendo al sustento de la desdichada familia» («Crimen abominable», El Motín, 20 octubre 1910). 
Junto al melodrama sentimental, coexiste la épica. Los periódicos anticlericales tienen un empeño especial en destacar los actos de rebeldía e indignación popular, a veces, ejecutados por las madres, para ahuyentar o capturar a los clérigos desenfrenados ${ }^{111}$. Destacan asimismo los actos de resistencia y protesta colectiva más o menos espontáneos, encaminados a impedir que los delitos quedaran impunes: los tumultos injuriando o intentando agredir al autor de las fechorías ${ }^{112}$, el apedreamiento de centros religiosos o la tentativa de incendiarlos ${ }^{113}$, las manifestaciones y mítines de repulsa ${ }^{114}$, gestos de justicia popular que contrastan con la opacidad y parsimonia de la magistratura, siempre sospechosa de coaligarse con el clericalismo ${ }^{115}$. Lo que está en juego es la dicotomía dominante en el discurso republicano español, oponiendo al pueblo frente a los grupos privilegiados ${ }^{116}$. Estas expresiones colectivas de indignación llegan a ser presentadas como una suerte de anticipo o preparación de la revolución que habrá de aniquilar la Monarquía, donde, como en el clero, concurría el despotismo con la monstruosidad sexual ${ }^{117}$.

El cura pederasta, por su parte, aparecía alojado en un doble registro social. Sus contactos con las clases propietarias, encubridoras de sus desmanes, no lo convertían sin embargo, en un miembro de ese universo, donde actuaba, como se dijo, de aliado de la esposa y de enemigo del marido. Por una parte era avecindado con el mundo oscuro del lumpenproletariado; se movía en los bajos fondos, frecuentando prostíbulos de muchachos, manteniendo encuentros clandestinos con golfos que lo extorsionaban y chantajeaban, en urinarios y parques, en oscuros callejones, dando rienda suelta a sus aficiones con jóve-

111 «Un cura de Achuri (Bilbao) fue apaleado por un grupo de mujeres que le cogieron in fraganti mientras abusaba brutalmente de la inocencia de una niña de corta edad. Gracias a la oportuna intervención de unos guardias, el desalmado sacerdote no fue arrastrado por las calles de aquel pueblo, como pretendían hacer lo que se enteraron de hecho tan indigno de un ministro del Señor» («Buena Pullita», El Motín, 4 abril 1912).

112 «El clérigo sodomita de Salamanca», Las Dominicales del Libre Pensamiento, 4 octubre 1890; «El crimen de un cura», El Pais, 15 agosto 1902. «Cura sodomita», El Motín, 15 septiembre 1910.

113 «Nuevo crimen clerical», Las Dominicales del Libre Pensamiento, 29 noviembre 1902; «Niño maltratado», El Motín, 10 noviembre 1910.

114 «Los crímenes del clericalismo», La Publicidad, 12 julio 1902. «Frutos de la enseñanza religiosa», El Pueblo, 8 julio 1908.

115 «Los crímenes nefandos (...), cuando se hacen endémicos y la impunidad del silencio y del interesado disimulo los ampara, sólo los puede castigar la justicia popular» (Cantaclaro [Blasco Ibáñez]: «Contra la infamia monárquica», El Motín, 3 noviembre 1910).

116 PÉREZ LEDESMA, 2014: 60-69.

117 «En Roma, el pueblo indignado contra el hijo de un rey por atacar el honor de una matrona, se sublevó y abolió la monarquía. El pueblo con su instinto vio que aquel hecho no era un accidente, sino una consecuencia natural de la monstruosidad que encierra la institución monárquica» («El clérigo sodomita de Salamanca», Las Dominicales del Libre Pensamiento, 4 octubre 1890). 
nes mendigos y vagabundos ${ }^{118}$. En una época en que la novela, la criminología y el noticiario de sucesos trabajaban para distinguir, dentro de las clases subalternas, al proletariado disciplinado - laborioso, ahorrativo, previsor-, del subproletariado vago, nómada y rebelde ${ }^{119}$, el cura perverso quedaba confinado en esta segunda facción. Incapaz de socializar su instinto en la conformación de una familia, debido al voto de castidad, el sacerdote pederasta pertenecía al ámbito peligroso, primitivo y semisalvaje de los «fuera de la ley».

Este parentesco con el salvajismo primitivo aparece en el segundo registro. Al cura pederasta se le atribuía a menudo un origen campesino. La brutalidad del rústico conjugaba a la vez la posesión de instintos bestiales — desviados perversamente por el celibato forzado_- y un temperamento «místico», contrario a la modernidad y al progreso ${ }^{120}$. Fue en el agro español donde se reclutaron las huestes del carlismo. Esta imaginería que presentaba al cura como un enemigo asilvestrado de la clase trabajadora tenía un efecto inmediato sobre el público obrero de la periferia urbana, objetivo de los mensajes del anticlericalismo republicano.

\section{Coda final}

La campaña periodística contra los ataques pederásticos perpetrados por sacerdotes, constituye un síntoma revelador de las guerras culturales entre clericales y anticlericales, que tuvieron lugar no sólo en España, sino en el conjunto del espacio europeo. Estas batallas alcanzaron su clímax entre la coyuntura finisecular y la primera década del siglo XX. Tomando como pretexto estos desmanes, el clero era presentado por sus detractores como un verdadero «enemigo biológico» de la nación, cuyos abusos sexuales arruinaban la hombría y el futuro de la comunidad nacional. Este perfil «biopolítico» ${ }^{121}$ del pánico moral suscitado por la campaña merece ser estudiado a escala trasnacional, confrontando sus distintas modulaciones en los países europeos. En cualquier

${ }^{118}$ Aparte del caso del cura Melías, El Globo, 21 enero 1901, véase el artículo publicado a raíz de la detención del Padre Segismundo Prat. Se refiere a frailes y sacerdotes merodeando, en Barcelona, urinarios, casas clandestinas de prostitución masculina, parques, «sospechosas estaciones», encontrándose con «chulillos» y jóvenes vagabundos, «San Estetismo Bendito», El País, 8 noviembre 1901.

119 VÁZQUEZ GARCÍA y MORENO MENGÍBAR, 1997: 248-249.

120 «Es evidente, está probado que todas esas elevaciones místicas y esas etéreas purezas antinaturales van a parar siempre ahí, a vicios secretos o a monstruosidades abominables. Está probado que cuanto más místico es un país y más abundan en él las órdenes religiosas, esos vicios van aumentando. En España desde la Restauración, ha tomado el mal proporciones aterradoras» («Violación de niños. Escándalo monstruo», El País, 30 junio 1899).

${ }^{121}$ Sobre esta vertiente biopolítica, VÁZQUEZ GARCÍA, 2018. 
caso, esta orientación biopolítica convertía al movimiento secularizador impulsado por los anticlericales en una empresa de verdadera «higiene social». La escuela, la beneficencia, la política penal y la protección de la infancia «peligrosa» y «en peligro» se convertían en blancos preferentes de la acción de los grupos anticlericales, cuya intervención de este modo no se limitaba a cuestionar el control de la esfera doméstica ejercido por los sacerdotes a través de su influencia sobre las almas y los cuerpos femeninos.

Por otra parte, en su capacidad para interconectar recíprocamente las identidades de clase, de edad y de género, en un contexto de crisis del proyecto nacionalizador, la campaña contra el clero pederasta funcionó en España como una argamasa para unir en un mismo frente a todos los que combatían el régimen de la Restauración: republicanos de distinta orientación, anarquistas y socialistas. Incluso el sector más clerófobo del liberalismo gubernamental se hizo eco de este pánico social. Sirvió también para justificar, en un terreno tan sensible como el de la cuestión escolar y la emergente protección de la infancia, las tentativas reformistas -insuficientes para los radicales-, de Canalejas, favorables a una mayor intervención estatal en dominios controlados por la Iglesia Católica. Pero esa cruzada contra la pederastia de los tonsurados no sobrevivió al retroceso del anticlericalismo acaecido tras el asesinato, en 1912, de quien presidía el gabinete liberal ${ }^{122}$.

\section{BibLIOGRAFÍA}

Álvarez Junco, José, El Emperador del Paralelo. Lerroux y la demagogia populista, Madrid, Alianza Editorial, 1990.

Álvarez Junco, José, «La nación en duda», en Juan Pan-Montojo (coord.), Más se perdió en Cuba. España, el 98 y la crisis de fin de siglo, Madrid, Alianza Editorial, 1998: 405-475.

Álvarez Junco, José, Alejandro Lerroux. El Emperador del Paralelo, Madrid, Editorial Síntesis, 2005.

Álvarez Uría, Fernando y Varela, Julia, Arqueología de la escuela, Madrid, La Piqueta, 1991.

Ambroise-Rendu, Anne Claude, «Enfants violés, quels enjeux pour la presse populaire fin de siècle?», A contrario, 12/2 (Paris, 2009): 13-25.

122 «Casi podríamos decir que antiguamente la gente de sotana daba tema para una crónica diaria, en la que se ponía de manifiesto la masculinidad de algún cura, la sensualidad sodomita de algún hermano Flaminio, la rapacidad de algún jesuita o el arrepentimiento de alguna monja deseosa de ser madre electiva, pero ya las prensas no gimen por las causas mencionadas, y no es precisamente que hayamos pasado a mejor vida social, sino que los presuntos protagonistas de la crónica mundanal y escandalosa, aumentan sus precauciones en vez de refrenar sus vicios y concupiscencias» («Entre curas», El Motín, 16 marzo 1916). 
Ambroise-Rendu, Anne Claude, Histoire de la pédophilie, XIXe-XXIe siècle, Paris, Fayard, 2014.

Angenot, Marc, «L'anticléricalisme», en 1889. Un état du discours social, París, Médias, 2014, capítulo 34, disponible en: http://www.medias19.org/index. php?id=12317 [consultado el 20 de agosto de 2017].

Arandilla Navajo, Manuel, «La Iglesia y Galeote», en Julia Varela y Fernando Álvarez-Uría, El cura Galeote, asesino del obispo de Madrid-Alcalá, Madrid, La Piqueta, 1979: 174-209.

Aresti, Nerea, Peters, Karin y Brühne, Julia (eds.), ¿La España invertebrada? Masculinidad y nación a comienzos del siglo XX, Granada, Comares, 2016.

Aubert, Pierre, «Luchar contra los poderes fácticos: el anticlericalismo», en Pierre Aubert (ed.), Religión y sociedad en España (siglos XIX y XX), Madrid, Casa de Velázquez, 2002: 219-253.

Ballester, Rosa y Balaguer, Emilio, «La infancia como valor y como problema en las luchas sanitarias de principios de siglo en España», Dynamis, 15 (Granada, 1995): 177-192.

Barona, Josep Lluis, «¿Por qué mueren los niños? El debate ideológico sobre la salud infantil en la sociedad española (1904-1939)», en Ricardo Campos, Luis Montiel y Rafael Huertas (coords.), Medicina, ideología e historia en España (siglos XVIXXI), Madrid, CSIC, 2007: 287-299.

Becker, Howard S., Outsiders. Études de sociologie de la déviance, Paris, Métailié, 1985.

Behlmer, George K., Child Abuse and Moral Reform in England 1870-1908, Stanford, Stanford University Press, 1982.

Berco, Christian, Sexual Hierarchies, Public Status. Men, Sodomy and Society in Spain's Golden Age, Toronto, University of Toronto Press, 2007.

Borrás Llop, José María (dir.), Historia de la infancia en la España Contemporánea 1834-1936, Madrid, Ministerio de Trabajo y Asuntos Sociales, Fundación Germán Sánchez Ruipérez, 1996.

Borutta, Manuel, Antikatolizismus. Deustchland und Italien im Zeitalter der europäischen Kulturkämpfe, Göttingen, Vandenhoeck und Ruprecht, 2010.

Cabrera, Miguel Ángel, Historia, lenguaje y teoría de la sociedad, Madrid, Cátedra, 2001.

Carrasco, Raphäel, Inquisición y represión sexual en Valencia (1565-1785), Barcelona, Laertes, 1985.

Castro Alfín, Demetrio, «Cultura, Política y cultura política en la violencia anticlerical», en Rafael Cruz y Manuel Pérez Ledesma (eds.), Cultura y movilización en la España Contemporánea, Madrid, Alianza Universidad, 1997: 69-97.

Charnon-Deutsch, Lou, «Cartoons and the Politics of Masculinity in the Spanish and American Press during the Warof 1898», Prisma Social, 13 (Las Matas, 201415): 109-148.

Clark, Christopher y Kaiser, Wolfram, «Introduction. The European Culture Wars», en Christopher Clark y Wolfram Kaiser, Culture Wars. Secular-Catholic Con- 
flict in Nineteenth-Century Europe, Cambridge, Cambridge University Press, 2003: 1-10.

Código penal reformado, Madrid, Imp. del Ministerio de Gracia y Justicia, 1970, disponible en https://sirio.ua.es/libros/BDerecho/codigo_penal/ima0121.htm [consultado el 24 de agosto de 2017].

Conard, Pierre, «Sexualité et anticlericalisme (Madrid, 1910)», Hispania. Revista Española de Historia, 117 (Madrid, 1971): 103-131.

Connell, Raewyn W. y Messerschmidt, James W., «Hegemonic Masculinity. Rethinking the Concept», Gender and Society, 19/6 (Londres, 2005): 829-859.

De la Cueva Merino, Julio, «Movilización política e identidad anticlerical, 1898-1910», Ayer. Revista de Historia Contemporánea, 27 (Madrid, 1997): 101-125.

De la Cueva Merino, Julio, «The assault on the city of Levites: Spain», en Christopher Clark y Wolfram Kaiser, Culture Wars. Secular-Catholic Conflict in Nineteenth-Century Europe, Cambridge, Cambridge University Press, 2003: 181-201.

De la Cueva Merino, Julio y Montero García, Feliciano, «Clericalismo y anticlericalismo en torno a 1898: percepciones recíprocas», en Rafael Sánchez Mantero (coord.), En torno al «98»: España en el tránsito del siglo XIX y XX. Actas del IV Congreso de la Asociación de Historia Contemporánea, vol. 2, Huelva, Universidad de Huelva, 2000: 49-64.

Del Cura González, Mercedes, Medicina y Pedagogía. La construcción de la categoría «infancia anormal» en España (1900-1939), Madrid, CSIC, 2011.

Delaunay, Jean-Marc, «Des refugés en Espagne. Les religieux français et les du 29 mars 1880», Mélanges de la Casa de Velázquez, 17 (Madrid, 1981): 291-319.

Delgado, Manuel, Las palabras de otro hombre. Anticlericalismo y misoginia, Barcelona, Muchnik Editores, 1993.

Delgado, Manuel, La ira sagrada. Anticlericalismo, iconoclastia y antirritualismo en la España contemporánea, Barcelona, RBA Libros, 2012.

Dittrich, Lisa, Antiklerikalismus in Europa. Öffenlichkeit und Säkularisierung in Frankreich, Spanien und Deustchland (1848-1914), Göttingen, Vandenhoeck und Ruprecht, 2014.

Dittrich, Lisa, «Propuestas para una interpretación europea del anticlericalismo en el siglo XIX: historia cultural, identidad y secularización», Historia Social, 14 (Valencia, 2016): 113-139.

Donovan, James M., «Combatting the Sexual Abuse of Children in France, 18251913», Criminal Justice History, 15 (Westport, 1994): 59-93.

Dufour, Gérard, Clero y sexto mandamiento. La confesión en la España del siglo XVIII, Valladolid, Ámbito, 1996.

Fernández, Pura, Eduardo López Bago y el naturalismo radical, Amsterdam, Atlanta, Rodopi, 1995.

Fernández, Pura, «Emotional Readings for New Interpretative Communities in the Nineteeth Century», en Luisa Elena Delgado, Pura Fernández y Jo Labanyi, Engaging the Emotions in Spanish Culture and History, Nashville, Vanderbilt University Press, 2016: 56-76. 
Fernández Soria, Juan Manuel y Mayordomo Pérez, Alejandro, «Perspectiva histórica de la protección a la infancia en España», Historia de la Educación. Revista Interuniversitaria, 3 (Salamanca, 1984): 191-213.

Fraile, Pedro, Un espacio para castigar. La cárcel y la ciencia penitenciaria en España (siglos XVIII-XIX), Barcelona, Ediciones del Serbal, 1987.

Goode, Erich y Ben-Yehuda, Nachman (eds.), Moral Panics. The Social Construction of Deviance, Oxford, Wiley-Blackwell, 2009.

Gross, Michael B., The War against Catholicism. Liberalism and the Anti-Catholic Imagination in Nineteenth-Century Germany, Ann Arbor (Mich.), The University of Michigan Press, 2004.

Guereña, Jean-Louis, La prostitución en la España contemporánea, Madrid, Marcial Pons, 2003.

Guereña, Jean-Louis, «La chasse à l'obscene. Politiques et mouvements antipornographiques en Espagne à la fin du XIXe siècle et au debut du XXe», en JeanClaude Seguin (dir.), L'obscène, París, Le GRIMH-LCE-GRIMIA, 2006: 15-30.

Guereña, Jean-Louis, Les espagnols et le sexe, XIXe-XXe siècles, Rennes, Presses Universitaires de Rennes, 2013.

Haliczer, Stephan, Sexualidad en el confesionario (un sacramento profanado), Madrid, Siglo XXI, 1998.

Jackson, Louise A., Child Sexual Abuse in Victorian England, Londres y Nueva York, Routledge, 2000.

Jansoone, David, L'affaire flamidien: une illustration de l'âpreté des tensions scolaires et religieuses à Lille à la fin du XIXe siècle, mémoire de maîtrise, Histoire, Lille, Université de Lille 3 (inédito).

Jenkins, Philip, Moral Panic. Changing Concepts of the Child Molester in Modern America, New Haven y London, Yale University Press, 1998.

Jenkins, Philip, Paedophiles and Priest. Anatomy of a Contemporary Crisis, Oxford y New York, Oxford University Press, 2001.

Jones, Gareth S., Lenguajes de clase. Estudios sobre la historia de la clase obrera inglesa, Madrid, Siglo XXI, 1989.

Kayser, Wolfram, "'Clericalism - That is Our Enemy!': European Anticlericalism and the Culture Wars», en Christopher Clark y Wolfram Kaiser, Culture Wars. Secular-Catholic Conflict in Nineteenth-Century Europe, Cambridge, Cambridge University Press, 2003: 47-76.

Kertzer, David I., El secuestro de Edgardo Mortara, Córdoba, Editorial Berenice, 2017.

Labanyi, Jo, Gender and Modernization in the Spanish Realist Novel, Oxford y Nueva York, Oxford University Press, 2000.

Loredo Narciandi, José Carlos, «Cultivar bebés, gobernar ciudadanos: un viaje de ida y vuelta por la puericultura española moderna», Revista de Historia de la Psicología, 37 (Madrid, 2016): 47-54.

Loredo Narciandi, José Carlos y Jiménez Alonso, Belén, «Pequeños ciudadanos: la construcción de la subjetividad infantil en la primera puericultura española e hispanoamericana», Universitas Psychologica, 13/5 (2014), [en línea], http://dx.doi.org/10.11144/Javeriana.upsy13-5.pccs. 
Louzao Villar, Joseba, «La recomposición religiosa en la modernidad: un marco conceptual para comprender el enfrentamiento entre laicidad y confesionalidad en la España Contemporánea», Hispania Sacra, 59 (Madrid, 2008): 331-354

Miguélez-Carballeira, Helena, «El imperio interno: discursos sobre masculinidad e imperio en los imaginarios nacionales español y catalán del siglo XX», Cuadernos de Historia Contemporánea, 39 (Madrid, 2017): 105-128.

Mitchell, Thomas, Betrayal of the Innocents. Desire, Power, and the Catholic Church in Spain, Philadelphia, University of Pennsylvania Press, 1998.

Molina Martínez, José Luis, Anticlericalismo y literatura en el siglo XIX, Murcia, Universidad de Murcia, 1998.

Nakens, José, Calumnias al clero, Madrid, La Itálica, 1915.

Perdiguero Gil, Enrique (comp.), Salvad al niño. Estudios sobre la protección a la infancia en la Europa mediterránea a comienzos del siglo XX, Valencia, Seminari d'Estudis sobre la Ciència, 2004.

Pérez Ledesma, Manuel, «Studies on anticlericalism in Contemporary Spain», International Review of Social History, 46/2 (Cambridge, 2001): 227-255.

Pérez Ledesma, Manuel, La construcción social de la historia, Madrid, Alianza Editorial, 2014

Rodríguez, Rocío, Sodomía e Inquisición: el miedo al castigo, Conesa, Usuhaia, 2014.

Salomón Chéliz, $\mathrm{M}^{\mathrm{a}}$ Pilar, «El discurso anticlerical en la construcción de una identidad nacional española republicana (1898-1936)», Hispania Sacra, 54 (Madrid, 2002): 485-497.

Salomón Chéliz, $\mathrm{M}^{\mathrm{a}}$ Pilar, «Beatas sojuzgadas por el clero: la imagen de las mujeres en el discurso anticlerical en la España del primer tercio del siglo XX», Feminis$\mathrm{mo} / \mathrm{s}, 2$ (Alicante, 2003): 41-58.

Salomón Chéliz, $\mathrm{M}^{\mathrm{a}}$ Pilar, «Las mujeres en la cultura política republicana: religión y anticlericalismo», Historia Social, 53 (Valencia, 2005): 103-118.

Salomón Chéliz, Ma Pilar, «Devotas mojigatas, fanáticas y libidinosas. Anticlericalismo y antifeminismo en el discurso republicano a fines del siglo XIX», en Ana M. Aguado y Teresa María Ortega López (coords.), Feminismos y antifeminismos: culturas políticas e identidades de género en la España del siglo XX, Valencia, Universitat de València, 2011: 71-98.

Sanabria, Enrique A., Republicanism and Anticlerical Nationalism in Spain, New York, Palgrave MacMillan, 2009.

Sánchez, Rosalía, «Los viejos verdes», El Mundo, 16 de septiembre 2013, http:// www.elmundo.es/elmundo/2013/09/16/internacional/1379354396.html [consultado el 12 de febrero de 2018].

Sanfeliú, Luz, «Ser hombre, ser ciudadano: identidades masculinas en el blasquismo», Millars: Espai i Historia, 32 (Castellón, 2009): 53-69.

Sarrión Mora, Adelina, Sexualidad y confesión. La solicitación ante el Tribunal del Santo Oficio (siglos XVI-XIX), Madrid, Alianza Universidad, 1994.

Schaeffer, Bernard, Les grandes affaires criminelles du Nord, Paris, De Borée, 2008.

Sirera Miralles, Carles, Un titulo para las clases medias. El Instituto de bachillerato Lluís Vives de Valencia, 1859-1902, Valencia, Publicaciones Universidad de Valencia, 2011. 
Soria, Carlos, «La Ley Española de Policía de Imprenta de 1883», Documentación de las Ciencias de la Información, 6 (Madrid, 1982): 11-40.

Suárez Cortina, Manuel, «Anticlericalismo, religión y política durante la Restauración», en Emilio La Parra López y Manuel Suárez Cortina (eds.), El anticlericalismo en la España contemporánea. Para comprender la laicización de la sociedad, Madrid, Biblioteca Nueva, 1998: 127-210.

Suárez Cortina, Manuel, Entre cirios y garrotes. Política y religión en la España contemporánea, 1808-1936, Santander y Cuenca, Editorial de la Universidad de Cantabria, Ediciones de la Universidad de Castilla-La Mancha, 2014.

Thomas, María, La fe y la furia. Violencia anticlerical popular e iconoclasta en España, 1931-1936, Granada, Comares, 2014.

Trinidad Fernández, Pedro, La defensa de la sociedad. Cárcel y delincuencia en España (siglos XVIII-XX), Madrid, Alianza Universidad, 1994.

Tsuchiya, Akiko, Marginal Subjects. Gender and Deviance in Fin-de-siècle Spain, Toronto, Buffalo, Londres, Toronto University Press, 2011.

Vázquez García, Francisco, «Foucault, el anticlericalismo y la genealogía del sacerdote pedófilo», Ponencia presentada en el V Congreso Internacional La actualidad de Michel Foucault, Madrid, 8 de marzo de 2018, Facultad de Filosofía, Universidad Complutense de Madrid, https://www.youtube.com/watch?v=592DA8t4F0\&feature=player_embedded, [consultado el 20 de abril de 2018].

Vázquez García, Francisco y Cleminson, Richard, Los Invisibles. Una historia de la homosexualidad masculina en España 1850-1939, Granada, Comares, 2011.

Vázquez García, Francisco y Moreno Mengíbar, Andrés, Sexo y razón. Una genealogía de la moral sexual en España (siglos XVI-XX), Madrid, Akal, 1997.

Verhoeven, Timothy, Transatlantic Anti-Catholicism. France and the United States in the Nineteenth Century, Basingstoke, Palgrave Mac Millan, 2010.

Vincent, Mary, «Made Flesh? Gender and Doctrine in Religious Violence in TwentiethCentury Spain», en Joanna De Groot and Sue Morgan, Sex, Gender and the Sacred. Reconfiguring Religion in Gender History, Oxford, Blackwell, 2014: 272-284.

Walker, Diana J., Crime at El Escorial. The 1892 Child Murder, the Press and the Jury, Lanham, University Press of America, 2014.

Witte, Els, «The Battle for Monasteries, Cemeteries and Schools: Belgium», en Christopher Clark y Wolfram Kaiser, Culture Wars. Secular-Catholic Conflict in Nineteenth-Century Europe, Cambridge, Cambridge University Press, 2003: 102-128.

Wolff, Larry, Postcards from the End of the World. Child Abuse in Freud's Vienna, New York, Atheneum, 1988.

Zabalzagoitia Herrera, Mauricio (ed.), Hombres en peligro. Género, nación e imperio en la España de cambio de siglo (XIX-XX), Madrid/Frankfurt, Iberoamericana/Vervuert, 2017.

Recibido: 23/10/2017

Aceptado: 16/05/2018

Hispania, 2018, vol. LXXVIII, nº. 260, septiembre-diciembre, págs. 759-786, ISSN: 0018-2141, e-ISSN: 1988-8368 https://doi.org/10.3989/hispania.2018.018 